\title{
KINETICS OF THE OXYGEN EVOLUTION REACTION ON RHODIUM ELECTRODES WITH DIFFERENT ELECTROCATALYTIC ACTIVITY
}

\author{
C. PALlOTTA, N.R. DE TACCONI and A.J. ARVIA * \\ Instituto de Investigaciones Fisicoquímicas Teóricas y Aplicadas. (INIFTA), División Elec- \\ troquímica, Sucursal 4-Casilla de Correo 16 (1900), La Plata (Argentina)
}

(Received 22nd September 1980)

It has recently been demonstrated [1] that the potentiodynamic behaviour of $\mathrm{Rh} / \mathrm{H}_{2} \mathrm{SO}_{4}(\mathrm{aq})$ interphases in the potential range of the thermodynamic stability of bulk water is associated with at least two-well defined and different electrochemical characteristics of rhodium, which were referred to as Aand B-type Rh electrodes [1]. The aim of the present report is to show the electrocatalytic difference of A- and B-type electrodes for the $\mathrm{O}_{2}$ evolution reaction, on the basis that the corresponding structures of the electrodes remain stable during the time the electrochemical measurements last.

The working electrodes are smooth polycrystalline $\mathrm{Rh}$ wires (spectroscopically pure Johnson, Matthey) which were treated as indicated elsewhere [1]. Experiments were made in $12 \mathrm{M} \mathrm{H}_{2} \mathrm{SO}_{4}$ at $25^{\circ} \mathrm{C}$. The influence of the anion adsorption, which is well known for the case of $\mathrm{HSO}_{4}^{-}$[2], is taken as a constant contribution in the experiments. The electrolytic solution was prepared from $96 \%$ A.R. sulphuric acid and triply distilled water. The solution satisfied the usually accepted purity requirements as determined through the potentiodynamic $E / I$ display run on Pt electrodes [3]. A reversible hydrogen electrode in the same solution was taken as a reference. The working electrode was subjected to the complex linear type potential/time perturbation functions $[4,5]$ as described later.

The A-type Rh electrodes are characterized by an $E / I$ potentiodynamic profile in the 0-1.60 V range (vs. RHE), which involves the already known contributions of the $\mathrm{H}$-electrosorption/H-electrodesorption $(0.0-0.24 \mathrm{~V})$ and the O-electrosorption/O-electrodesorption (0.6-1.6 V) (Fig. 1). These electrodes were first subjected to repetitive triangular potential sweeps (RTPS) in the $0-1.60 \mathrm{~V}$ range at one preset potential sweep rate $(v)$ in the $0.03 \mathrm{~V} \mathrm{~s}^{-1} \leqslant$ $v \leqslant 0.3 \mathrm{~V} \mathrm{~s}^{-1}$ range in order to attain a stabilized $E / I$ display. Afterwards the anodic switching potential was extended to $2.0 \mathrm{~V}$. When the potential exceeds $1.7 \mathrm{~V}$ an abrupt increase of the anodic current is observed which corresponds to the $\mathrm{O}_{2}$ evolution reaction. The current contribution of the latter reaction was determined and plotted as a conventional Tafel line. A linear Tafel plot results when the anodic potential is $>1.76 \mathrm{~V}$ (Fig. 2). The slope of the linear

^ To whom correspondence should be addressed. 

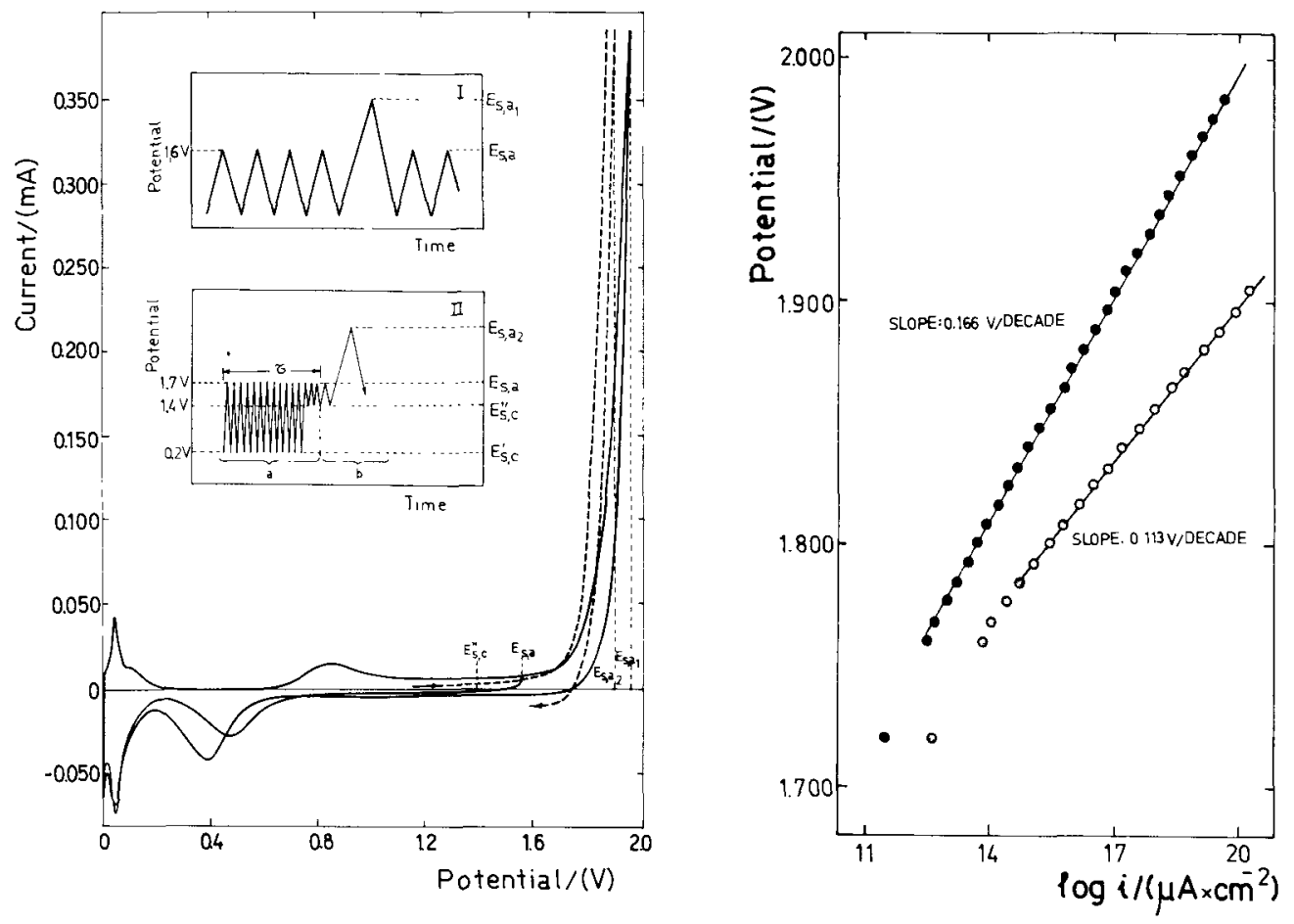

Fig. 1. Potentiodynamic $E / I$ profiles run at $0.03 \mathrm{~V} \mathrm{~s}^{-1}$ according to the potential perturbation programs indicated in the figure. The full trace corresponds to program I and the dotted trace corresponds to the last triangular potential sweep run after the previous complex potential/time perturbation indicated by program II. The initial RTPS between $E_{\mathrm{s}, \mathrm{c}}^{\prime}$ and $E_{\mathrm{s}, \mathrm{a}}$ and the intermediate RTPS between $E_{\mathrm{s}, \mathrm{c}}^{\prime \prime}$ and $E_{\mathrm{s}, \mathrm{a}}$ are run at $80 \mathrm{~V} \mathrm{~s}^{-1}$. The duration of the intermediate RTPS is $\tau=5 \mathrm{~min}$.

Fig. 2. Tafel plots obtained from the potentiodynamic $E / I$ displays run at $0.1 \mathrm{~V} \mathrm{~s}^{-1}$ with the potential perturbation program I. (•) A-type electrode; $(O)$ B-type electrode.

$E / \log i$ plots depend on $v$ (Fig. 3), and its value extrapolated at $v=0$, is 0.152 $\mathrm{V}$ decade ${ }^{-1}$, which is slightly higher than the previously reported results for the $\mathrm{O}_{2}$ evolution on rhodium under quasi-stationary conditions, probably because of the different electrolyte concentration [6-7]. The corresponding apparent exchange current density at $E=1.23 \mathrm{~V}$ is $10^{-8} \mathrm{~A} \mathrm{~cm}^{-2}$. It is interesting to emphasize that once the $\mathrm{O}_{2}$ evolution potential range has been swept, the potential excursion run immediately afterwards towards negative potentials exhibits a small broad cathodic current peak at $c a .0 .95 \mathrm{~V}$, followed by the predominant O-electrodesorption current peak. The latter, however, is shifted towards more negative potentials about $0.1 \mathrm{~V}$, with respect to the initially recorded cathodic current peak. This effect is accompanied by a cathodic charge increase in the $\mathrm{H}$-electrosorption potential range which has been attributed to the electroreduction of a fraction of a more stable $O$ species whose formation has been promoted at high positive potentials. Then, through adjusting $E_{\mathrm{s}, \mathrm{a}}$ to its initial value, the initial stabilized profile is immediately obtained. 
The B-type Rh electrodes are obtained through a RTPS between 1.7 and 0.2 $\mathrm{V}$ at $80 \mathrm{~V} \mathrm{~s}^{-1}$ for several minutes [8]. These electrodes are characterized by a stabilized potentiodynamic $E / I$ profile, including a fast response conjugated redox system in the $1.54-1.66 \mathrm{~V}$ range. Once this situation has been attained $v$ is changed from 80 to $0.03 \mathrm{~V} \mathrm{~s}^{-1} \leqslant v \leqslant 0.3 \mathrm{~V} \mathrm{~s}^{-1}$ and the anodic potential limit is extended to $1.9 \mathrm{~V}$ (Fig. 1 ) to cover a part of the $\mathrm{O}_{2}$ evolution potential range. The corresponding $E / I$ profile after $1.8 \mathrm{~V}$ exhibits a Tafel relationship, but with a slope remarkably lower than that of A-type electrodes (Fig. 2). In this case, the average Tafel slope is $0.110 \mathrm{~V}$ decade ${ }^{-1}$, a value which is practically independent of $v$ (Fig. 3 ). The apparent exchange current density extrapolated at $1.23 \mathrm{~V}$ is $4 \times 10^{-9} \mathrm{~A} \mathrm{~cm}^{-2}$. Therefore, at potentials more positive than $1.75 \mathrm{~V}$, B-type electrodes exhibit an appreciably larger electro-catalytic activity than the A-type electrodes.

On the other hand, after reaching the $\mathrm{O}_{2}$-evolution potential range, the B-type $\mathrm{Rh}$ electrodes exhibit a complex potentiodynamic response when the RTPS is continued at a low $v$, within a more restricted potential range, for instance when $E_{\mathrm{s}, \mathrm{a}}$ is fixed at a value where the electroformation of the $\mathrm{O}$ species on $\mathrm{Rh}$ can be neglected $\left(E_{\mathrm{s} . \mathrm{a}}=0.57 \mathrm{~V}\right)$ (Fig. 4$)$. The first potential
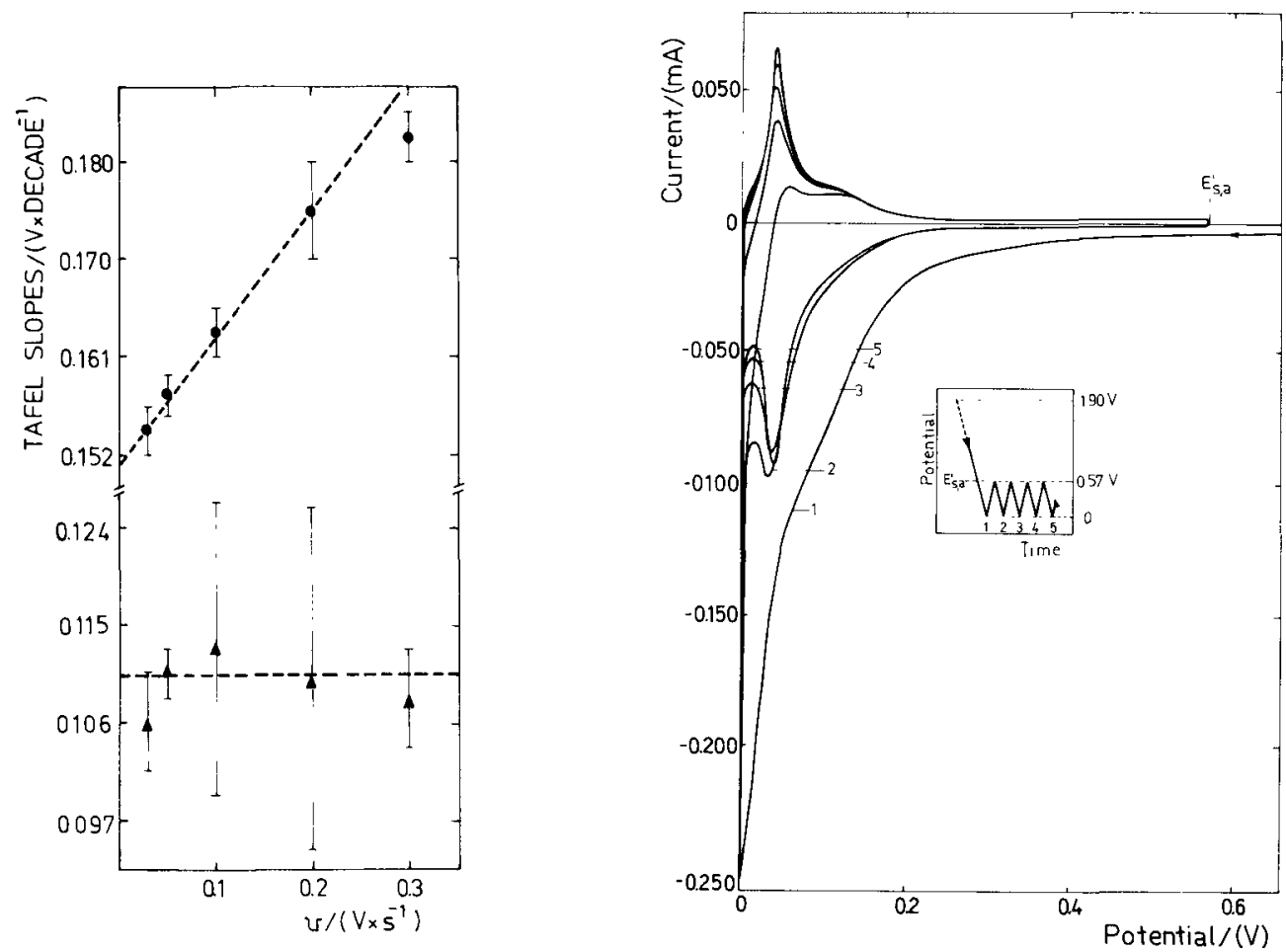

Fig. 3. Dependence of the Tafel slope on the potential sweep rate. (•) A-type electrode; $(O)$ B-type electrode.

Fig. 4. Gradual change of the potentiodynamic $E / I$ display in the H-electrosorption potential range starting from a B-type electrode. The potential perturbation program shown in the figure was run at $0.03 \mathrm{~V} \mathrm{~s}^{-1}$. 
sweep run under these conditions shows a cathodic charge $\left(Q_{c, H}\right)$ which is greater than the anodic charge $\left(Q_{a, H}\right)$ in the potential range of the H-electrosorption/H-electrodesorption reactions. The $Q_{c, H}-Q_{a, H}$ difference decreases with repetitive potential cycling. The greatest rate of decrease for $Q_{c, H}-Q_{a, H}$ is observed at the initial stage of the potential cycling. However, most of the cathodic charge playing a part in the initial stages should be related to the electroreduction of the $(\mathrm{O})$ species, since $Q_{\mathrm{a}, \mathrm{H}}$ starts with a value of only $c a$. $10 \%$ of $Q_{c, \mathrm{H}}$ during the first negative going potential excursion at $0.03 \mathrm{~V} \mathrm{~s}^{-1}$ from $E_{\mathrm{s}, \mathrm{a}}=1.9 \mathrm{~V}$. Finally, after approximately 40 cycles under the above-mentioned conditions, $Q_{\mathrm{c}, \mathrm{H}}=Q_{\mathrm{a}, \mathrm{H}}$ and the potentiodynamic $E / I$ profile becomes that which is already known in the conventional voltammograms reported in the literature.

From the sum of the $\left(Q_{\mathrm{c}, \mathrm{H}}-Q_{\mathrm{a}, \mathrm{H}}\right)$ charge differences extrapolated to $\left(Q_{\mathrm{c}, \mathrm{H}}-Q_{\mathrm{a}, \mathrm{H}}\right)=0$, an estimation of the charge playing a part in the electroreduction of the $\mathrm{O}$ species characterizing $\mathrm{B}$-type electrodes is made. The corresponding charge depends on $v$ and at $v=0 \mathrm{~V} \mathrm{~s}^{-1}$ its value is $5 \mathrm{mC} \mathrm{cm}{ }^{-2}$.

The potentiodynamic $E / I$ profile of B-type Rh electrodes is gradually approached when the $\mathrm{Rh}$ electrodes have been potentiodynamically aged in the O-electrosorption/O-electrodesorption potential range. This depends on the potentiodynamic history of the Rh electrodes, particularly on $E_{s, \mathrm{a}}$ and $v$. Thus, the electrodes were prepared with a potentiodynamic perturbation involving in one case $E_{\mathrm{s} . \mathrm{a}}=1.2 \mathrm{~V}$ in order to achieve an $\mathrm{O}$ coverage of the order of one monolayer, and in the other case, $E_{\mathrm{s}, \mathrm{a}}=1.7 \mathrm{~V}$ to attain a larger $O$ coverage. In both cases, however, the potentiodynamic ageing was promoted by repetitively removing and reforming $60 \%$ of the $O$ coverage at either $v=0.05 \mathrm{~V} \mathrm{~s}^{-1}$ or $v=$ $0.1 \mathrm{~V} \mathrm{~s}^{-1}$, during a number of cycles of between 5 and 240 . The $60 \%$ of the $\mathrm{O}$ coverage produces the largest splitting and shift effect on the O-electroreduction current peak [1]. Thus, when the potentiodynamic perturbation of the $\mathrm{Rh}$ is confined to $E_{\mathrm{s}, \mathrm{a}}=1.2 \mathrm{~V}$, the $\mathrm{O}_{2}$-evolution Tafel plot yields a single straight line in the 1.76-2.02 $\mathrm{V}$ range for any number of cycles. The corresponding Tafel slope is $0.182 \mathrm{~V}$ decade ${ }^{-1}$, a value close to that of the A-type electrodes.

On the other hand, when the Rh electrode is perturbed at $0.1 \mathrm{~V} \mathrm{~s}^{-1}$ between $E_{\mathrm{s}, \mathrm{a}}=1.7 \mathrm{~V}$ and $E_{\mathrm{s}, \mathrm{c}}^{\prime}=0.39 \mathrm{~V}$, the Tafel plot involves two linear portions (Fig. 5), in accordance with the number of potential cycles. The lower part below $1.84 \mathrm{~V}$ exhibits an slope which changes in the $0.173-0.110 \mathrm{~V}^{\text {decade }}{ }^{-1}$. The other part found above $1.86 \mathrm{~V}$ has a slope which ranges between 0.173 and $0.157 \mathrm{~V}$ decade ${ }^{-1}$, depending on the number of potential cycles (Fig. 5). The definition of the two linear portions becomes more clearly distinguishable when the number of ageing cycles exceeds 12 or thereabouts (Fig. 6). The two slopes represent two limiting electrochemical behaviours, one at lower potentials and the other at high potentials, which are directly comparable to that referred to above for the B- and A-type Rh electrodes respectively. Therefore, as far as the $\mathrm{O}_{2}$ evolution is concerned the existence of two $E / \log I$ linear relationships whose transition potential depends on the number of potential cycles playing a part during the intermediate perturbation, is closely related to the nonstabilized surface conditions of the Rh electrode. This transition qualitatively resembles that reported in the literature for the stationary Tafel slopes obtained for the $\mathrm{O}_{2}$ evolution on $\mathrm{Rh}$ in more diluted perchloric acid electrolytes [6]. 


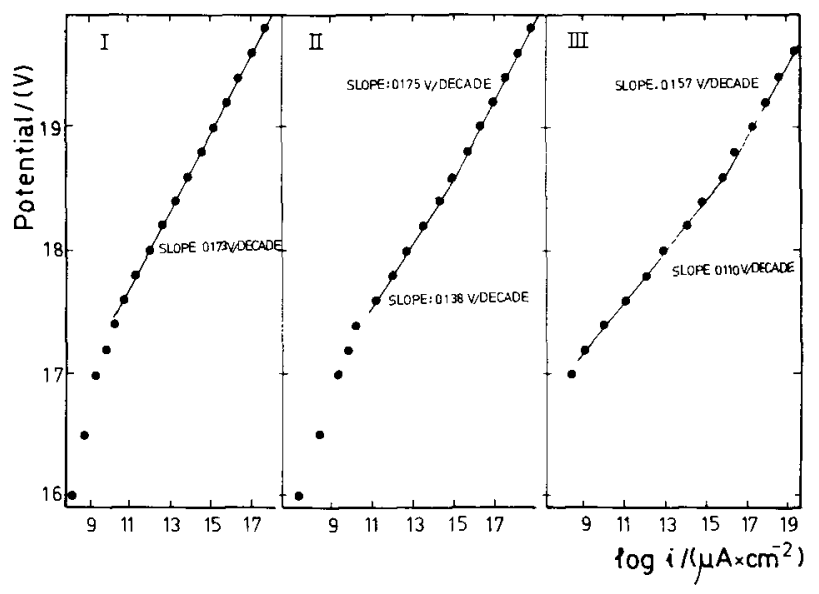

Fig. 5. Tafel plots obtained from the $E / I$ displays run at $0.1 \mathrm{~V} \mathrm{~s}^{-1}$ on potentiodynamically aged electrodes. Influence of the number of RTPS. (I) 5 RTPS; (II) 30 RTPS; (III) 180 RTPS.

Various interesting conclusions can be derived from the results described above. The fact that A-type Rh electrodes involve $v$-dependent Tafel slopes reveals the non-equilibrated nature of the $O$ species formed on the surface of those electrodes. On the contrary, B-type electrodes exhibit $v$-independent Tafel slopes and the corresponding surface is likewise completely stabilized. Otherwise, the largest electrocataly tic effect is associated with electrodes potentiodynamically perturbed at anodic potentials $>1.2 \mathrm{~V}$. This potential value has previously been related to the potential limit where the $O$ monolayer on $\mathrm{Rh}$ is electroformed [1,9]. Therefore, this means that an O-electrosorbed charge larger than that of the $\mathrm{O}$ monolayer is required in order to improve the electrocatalytic activity of $\mathrm{Rh}$ on the $\mathrm{O}_{2}$-evolution reaction. This is precisely the case when the B-type $\mathrm{Rh}$ electrodes are formed. Consequently, it is probable that the electrocatalytic activity is closely related to the formation of a

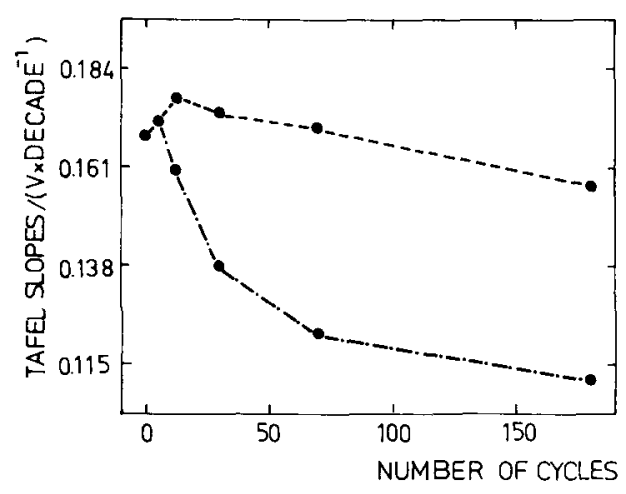

Fig. 6. Dependence of the Tafel slope on the number of ageing cycles. (- - - - -) Tafel slopes obtained at potentials $>1.86 \mathrm{~V} ;(\cdot-.-$. $)$ Tafel slopes obtained at potentials $<1.86 \mathrm{~V}$. 
peroxydic-type structure on the electrode surface, a conclusion which is supported by the good coincidence of the potential of the surface redox couple associated with the B-type electrodes and that of the $\mathrm{H}_{2} \mathrm{O} / \mathrm{H}_{2} \mathrm{O}_{2}$ redox reaction [7]. The Tafel slopes obtained with both A-type electrodes (at $v=0)$ and B-type electrodes cannot be directly compared to those related to relatively simple mechanisms for the $\mathrm{O}_{2}$-evolution reactions. For further advance in this respect the influence of the solution $\mathrm{pH}$ must be considered. However, the interesting fact that there is a net transition of the Tafel slope which depends on the activity changes produced at the electrode surface may help us to understand the changes of the stationary Tafel slope reported in the literature [7] at lower electrolyte concentrations, and correspondingly, the change of the mechanism of the $\mathrm{O}_{2}$-evolution reaction.

\section{ACKNOWLEDGEMENTS}

INIFTA is sponsored by the Consejo Nacional de Investigaciones Científicas y Técnicas the Universidad Nacional de La Plata and the Comision de Investigaciones Científicas (Provincia de Buenos Aires). This work was also partially sponsored by the Regional Program for the Scientific and Technological Development of the Organization of American States.

\section{REFERENCES}

1 C. Pallotta, N.R. de Tacconi and A.J. Arvía, Electrochim. Acta, in press.

2 V.S. Bagotskii, Yu.B. Vassivliev, O.A. Khazova and S.S. Sedova, Electrochim. Acta, 16 (1971) 913.

3 B.E. Conway, J. Angerstein-Kozlowska and W.B.A. Sharp, Anal. Chem., 45 (1973) 1331.

4 M.E. Folquer, J.O. Zerbino, N.R. de Tacconi and A.J. Arvía, J. Electrochem. Soc., 126 (1979) 592.

5 R. Cordova O., M.E. Martins and A.J. Arvía, Electrochim. Acta, 25 (1980) 453.

6 A. Damjanovic, A. Dey and J.O'M. Bockris, J. Electrochem. Soc., 113 (1966) 739.

7 A. Damjanovic in J.O'M. Bockris and B.E. Conway (Eds.), Modern Aspects of Electrochemistry, Vol. 5 , Butterworths, London, 1969, Ch. 5.

8 C. Pallotta, N.R. de Tacconi and A.J. Arvía, J. Electrochem. Soc., submitted for publication.

9 E.I. Khrushcheva, N.A. Shumilova and M.R. Tarasevich, Elektrokhimiya, 2 (1966) 277. 